\title{
Indicadores de Contaminación fecal en la subcuenca del Río Gil González
}

Lucía Vanegas.

Centro para la Investigación en Recursos Acuáticos de Nicaragua, Universidad Nacional Autónoma de Nicaragua, Apdo. Postal 4598, Managua, Nicaragua. Correo electrónico: lucia.vanegas@cira-unan.edu.ni

\section{RESUMEN}

El crecimiento de la población a nivel mundial y el aumento del uso del agua para diferentes actividades, ha incrementado los niveles de contaminación de origen doméstico e industrial a los cuerpos de agua. Los residuos de origen doméstico y la carga contaminante está representada por altos porcentajes de materia orgánica y microorganismos de origen fecal causantes de enfermedades de origen hídrico. Por la importancia que representa la subcuenca del rio Gil González para los Municipios de Belén, Potosí y Buenos Aires del Departamento de Rivas, cuyas aguas son utilizadas para riego, recreación, baño, abrevadero de ganado, y el uso de las aguas de pozos excavados para consumo, se llevo a cabo este estudio con el objetivo de determinar la calidad y disponibilidad de las aguas superficiales y subterráneas de la subcuenca del Rio Gil González a través de variables biológicas como Coliformes termotolerantes, Escherichia coli y Enterococos aplicando el método de tubos múltiples. Se realizaron dos muestreos en diferentes épocas del año, noviembre 2010 y abril 2011 encontrándose en todos los sitios altas concentraciones de indicadores de contaminación fecal. Los altos crecimientos bacterianos demuestran que todos los sitios analizados se encuentran seriamente contaminados por organismos fecales tanto de origen humano como de animales potenciando un alto riesgo a la salud de la población, aún en aquellos puntos donde se observan concentraciones bajas, haciendo el agua de los pozos no apta para consumo ni para riego y las aguas del rio se encuentra fuera de los límites permisibles para fines de recreación, baño.

Palabras Claves: contaminación fecal, Escherichia coli, enterococos, patógenos.

\section{INTRODUCCIÓN}

Dentro de la cuenca de los Grandes Lagos y el Rio San Juan (Cuenca No.69) se encuentra la

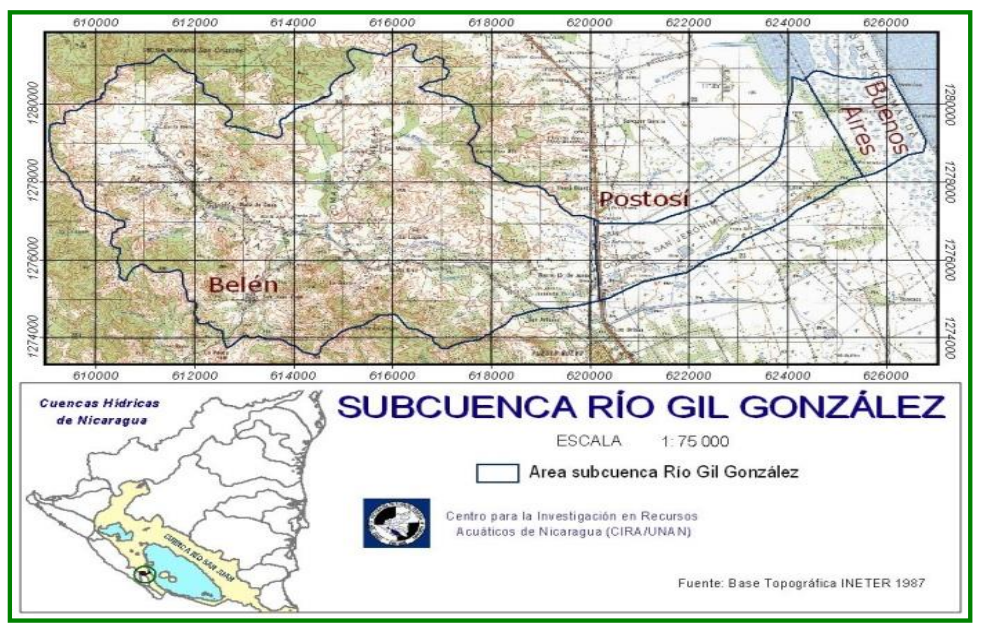

Figura 1. Área de estudio Potosí - San Jerónimo y en Buenos Aires la comarca de Tolesmaida. subcuenca del Río Gil González, ubicada en el flanco oeste del Lago Cocibolca. Geográficamente pertenece al departamento de Rivas. El Río Gil González constituye el más extenso y caudaloso rio de los municipios de Belén, Potosí y Buenos Aires localizado entre las coordenadas 609 y 627 este y las 1272 y 1282 norte (North American Datum de 1927, NAD27), con un área total de $68.43 \mathrm{Km}^{2}, \quad y$ un perímetro aproximado de $56.41 \mathrm{~km}$. La Subcuenca del Rio Gil González 
esta compartida por tres municipios (figura 1) Belén: $55.51 \mathrm{Km}$ que representan el $81 \%$ del área total de la subcuenca, Potosí 9.71Km (14\%) y Buenos Aires con 3.21 (5\%). En el municipio de Belén el Río Gil González cruza las comarcas Mata de Caña y Las Mesas.

El Centro para la Investigación en Recursos Acuáticos de Nicaragua (CIRA/UNAN) en coordinación con La Fundación Nicaragüense para el Desarrollo Sostenible (FUNDENIC SOS) y con apoyo financiero de la Unión Europea, llevo a cabo durante el año 2005 - 2006 un estudio en el rio Gil González que ayudara a entender los procesos que influyen en la calidad y disponibilidad del agua del Rio y tributarios a través de indicadores de contaminación fecal, encontrándose en ese entonces altos crecimientos bacterianos en los sitios Mata de Caña y las Mesas producto de la contaminación orgánica de origen humano y por animales, situación que se fue agravando hasta la fecha, lo cual se demostró en el estudio realizado en noviembre 2010 abril 2011 donde se analizaron además de las aguas del rio, aguas de pozos excavados.

Los resultados obtenidos durante las dos épocas demuestran que todos los sitios analizados se encuentran seriamente contaminados por organismos fecales tanto de origen humano como de animales, potenciando esto un alto riesgo a la salud de la población, creándose las condiciones adecuadas para la propagación de enfermedades transmitidas por el agua.

Siendo las aguas de la subcuenca del rio Gil Gonzalez un recurso vital para las diferentes actividades que se realizan, se hizo necesario evaluar el grado de contaminación de las aguas a través de indicadores de contaminación fecal, para ello se empleo el método de tubos múltiples o Número más Probable (NMP), el cual es aplicable tanto para aguas superficiales como subterráneas.

Según resultados obtenidos en los ríos y en los pozos analizados estos demuestran contaminación por Coliformes termotolerantes, Escherichia coli y Enterococos fecales, confirmando que la contaminación presente es producto de la presencia de animales, fecalismo al aire libre y de las condiciones higiénico-sanitarias que predominan con el sistema de extracción del agua de los pozos. El agua de los pozos no es apta para consumo ni para riego ya que sobrepasan las normas de calidad de agua, así también los ríos se encuentran fuera de los límites permisibles para fines de recreación.

Los recursos hídricos de nuestro país, se encuentran grandemente amenazados por procesos de contaminación que inciden en su calidad, por tal razón es fundamental la protección de las aguas de la subcuenca del Rio Gil González y su entorno, el cual tiene usos potenciales para el desarrollo económico y social de los pobladores del municipio de Belén, tales como: consumo humano, irrigación, turismo sostenible, entre otros. En vista de ello se pretende determinar la calidad y disponibilidad de las aguas de la subcuenca del Rio Gil González, mediante la cuantificación de variables biológicas identificando las áreas de mayor riesgo de contaminación.

\section{METODOLOGIA}

Se trabajo en la subcuenca del rio Gil González y sus principales tributarios, y en 6 pozos excavados de la zona (figura 2). Las variables en estudio fueron Coliformes termotolerantes, Escherichia coli y Enterococos fecales con el objetivo de diagnosticar la calidad de sus aguas. 
Para obtener la información se aplico la observación indirecta que ayudo a conocer con más detalle la zona en estudio y la observación directa a través de la cual se logro caracterizar el área, determinar los criterios para seleccionar los sitios de muestreo y las variables según la condición de cada sitio.

\section{Colecta de muestra}

La colecta de muestra de agua de rio para el análisis microbiológico Coliformes termotolerantes, Escherichia coli y Enterococos fecales se hizo utilizando un recipiente de plástico de 1

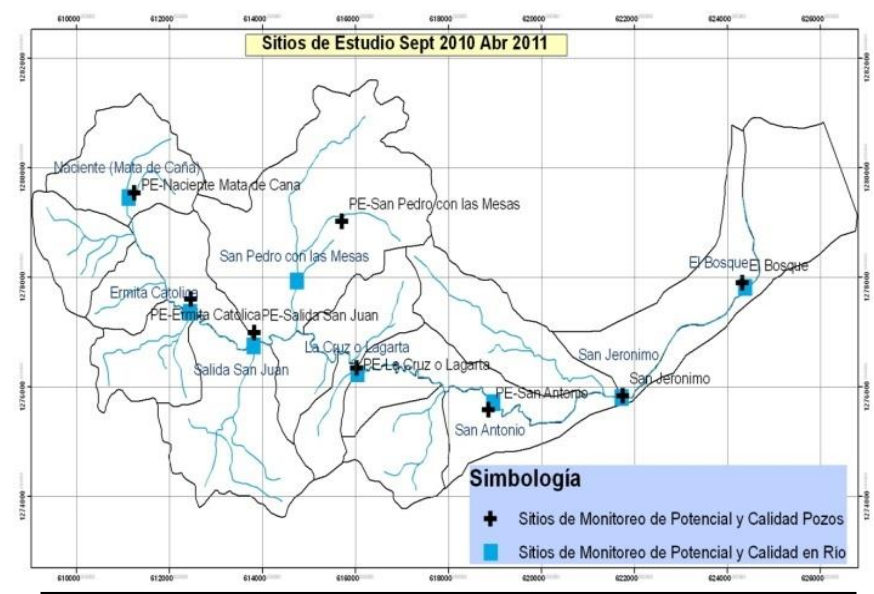

Figura 2. Sitios de estudio Nov. 2010 y Abril 2011 litro de capacidad, esterilizado, el cual fue sumergido a unos $20 \mathrm{~cm}$ de profundidad aproximadamente, luego de llenado se tapo y se guardo en termo con hielo hasta su transporte al laboratorio.

La colecta de muestra de agua de pozo excavado provisto de bomba de mecate, se hizo limpiando previamente la salida del agua con un algodón humedecido con alcohol y luego quemando para esterilizar, dejar correr al agua aproximadamente 2 min y luego llenar el frasco destapándolo al momento de la toma de muestra y después se guardo en termo con hielo hasta su transporte al laboratorio.

Los análisis para Coliformes termotolerantes, Escherichia coli y Enterococos fecales se realizaron aplicando la metodología del American Public Health Association (APHA, 2005)

\section{RESULTADOS}

\section{Calidad microbiológica y sanitaria en los ríos}

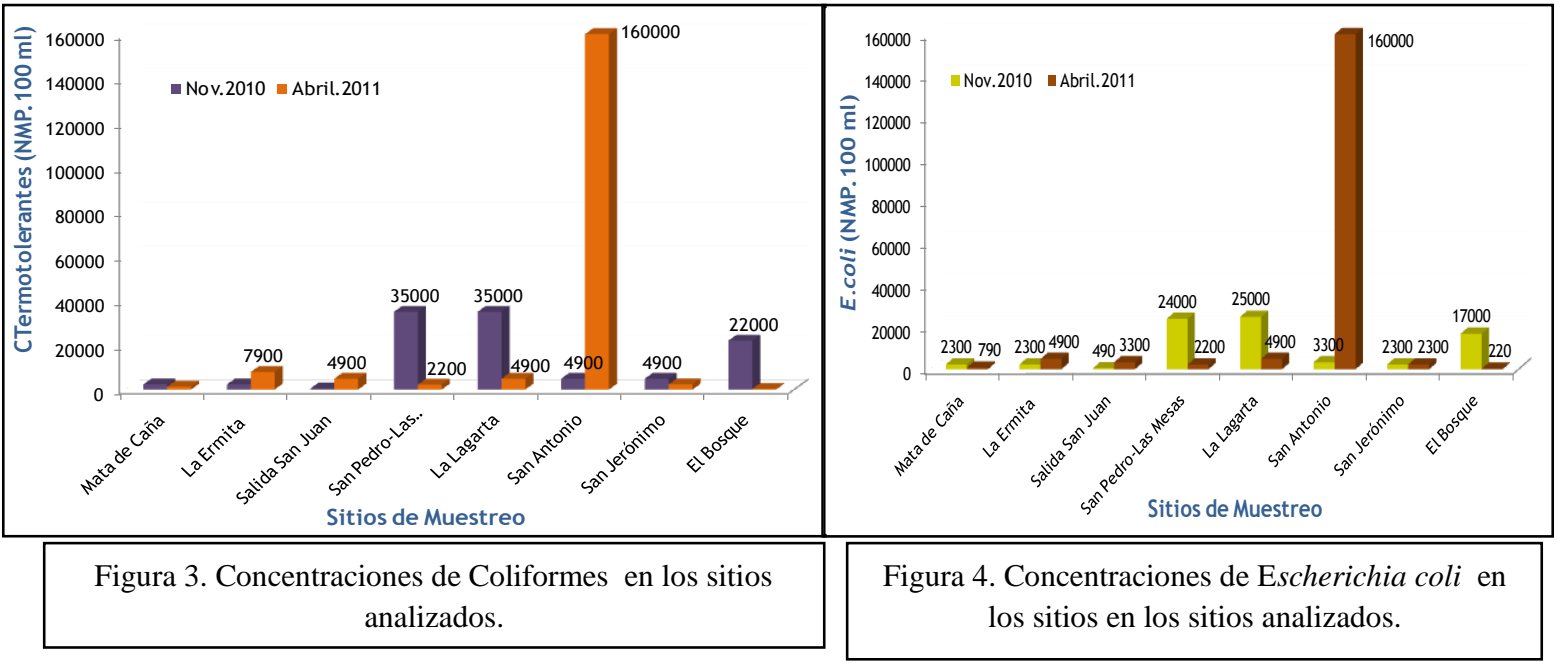

Se pudo observar en las figuras 3 y 4, que el sitio ubicado en el cauce principal del Rio Gil González en San Antonio para el mes de Abril 2011 fueron encontradas las concentraciones más altas (para ambas variables) de Coliformes termotolerantes y Escherichia coli con 160000 NMP. $100 \mathrm{ml}^{-1}$ evidenciando que este sitio está más expuesto a la influencia antropogénica. Durante 
el mes de Noviembre 2010, se presento un comportamiento bastante similar en los sitios San Pedro con Las Mesas, La Cruz o Lagarta y El Bosque

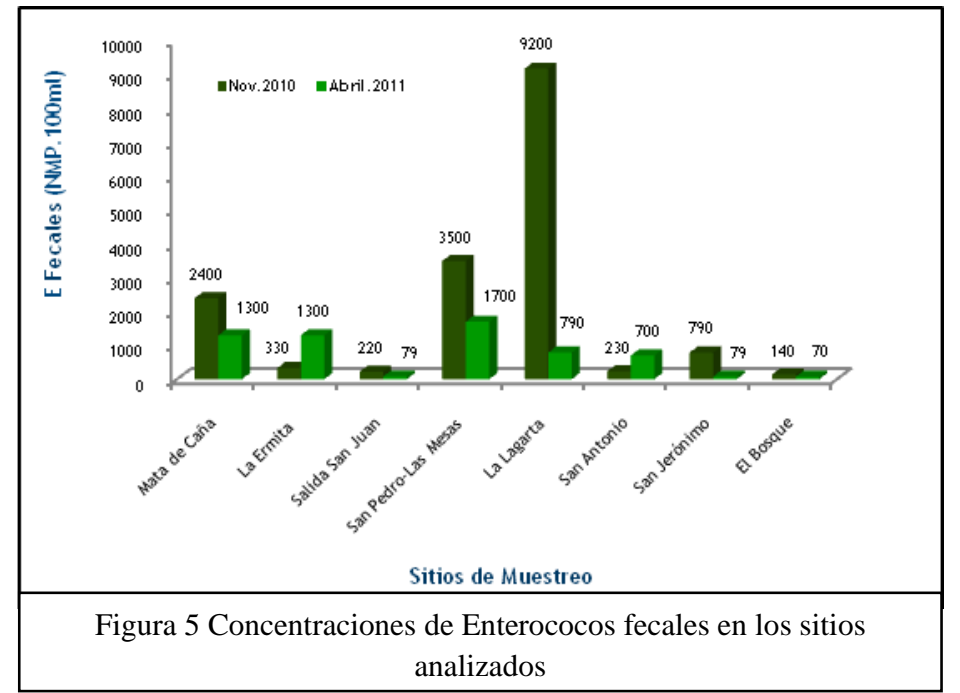

Las concentraciones de Enterococos fecales para Noviembre 2010 oscilaron entre 9200 y 140 NMP.100 $\mathrm{ml}^{-1}$ y en Abril 2011 de $1700-70$ NMP.100 $\mathrm{ml}^{-1}$ sobrepasando el valor guía para aguas de recreación de 33 enterococos por $100 \mathrm{ml}^{-1} \mathrm{La}$ agrupación más alta de Enterococos fecales fue obtenida en sitio La Cruz o La Lagarta con 9200 NMP. $100 \mathrm{ml}^{-1}$ para el mes de Noviembre 2010. (ver figura 5)

$\underline{\text { Calidad microbiológica y sanitaria en los pozos excavados }}$

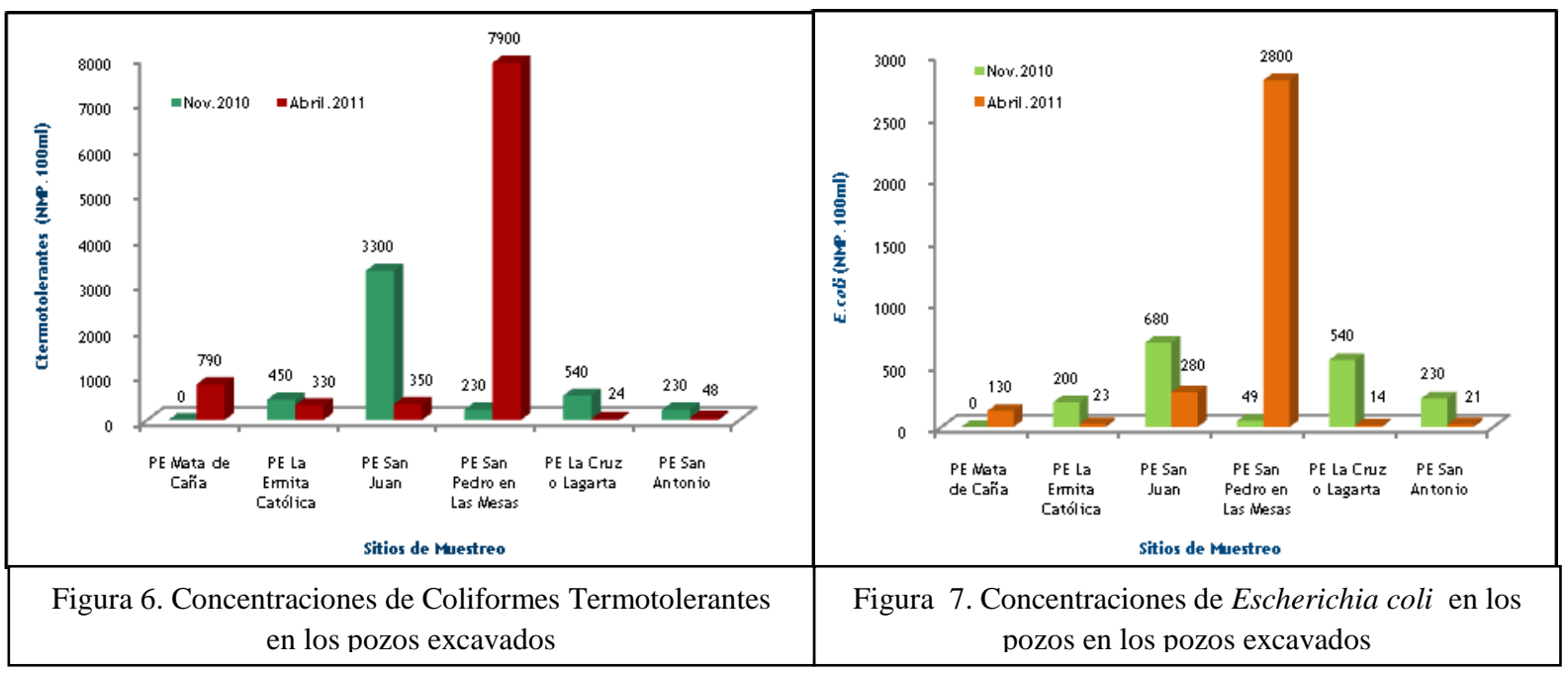

En el muestreo del mes de Noviembre 2010 en el pozo excavado ubicado en la comunidad San Juan fueron analizadas las concentraciones más altas con 3300 NMP.100 ml ${ }^{-1}$ de Coliformes termotolerantes y $680 \mathrm{NMP} .100 \mathrm{ml}^{-1}$ de Escherichia coli.

En el pozo excavado ubicado en la comunidad de San Pedro en Las Mesas durante el mes de Abril 2011 fueron encontradas las concentraciones más altas de Coliformes termotolerantes y Escherichia coli (Figuras 6 y 7), siendo de 7900 NMP. $100 \mathrm{ml}^{-1}$ para Coliformes termotolerantes y de 2800 NMP. $100 \mathrm{ml}^{-1}$ para Escherichia coli.

Los mayores crecimientos bacterianos de enterococos fecales (Figura 8) fueron analizados en el agua del Pozo excavado ubicado en la comunidad La Ermita durante la colecta del mes de Noviembre 2010, con 2400 NMP. $100 \mathrm{ml}^{-1}$. 
En Abril 2011, en el pozo ubicado en Mata de Caña se observo la concentración más alta de enterococos fecales con 490 NMP. $100 \mathrm{ml}^{-1}$.

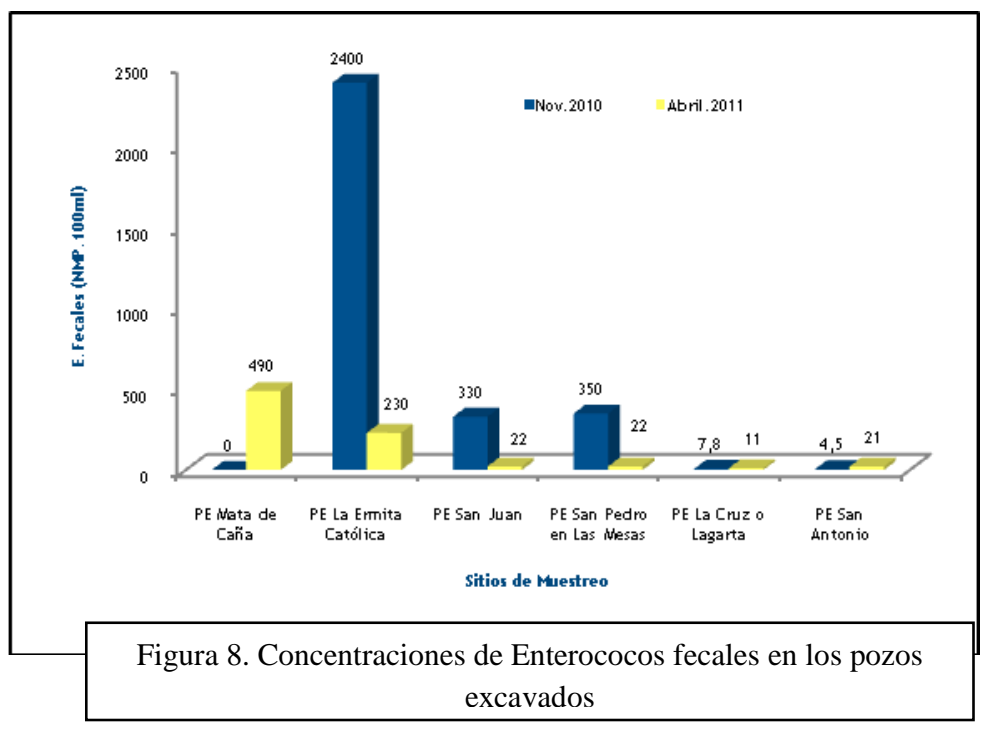

\section{DISCUSIÓN}

\section{$\underline{\text { Aguas superficiales }}$}

En ambos muestreos en todos los sitios analizados en los tributarios y cauce principal del Rio Gil González, los valores de Coliformes termotolerantes $\mathrm{y}$ Escherichia coli sobrepasaron los valores guías establecidos por la agencia de protección ambiental de los Estados Unidos (U.S. EPA, 1986), para el contacto directo y prolongado, los cuales deben ser de 200 coliformes termotolerantes por cada $100 \mathrm{ml}$ y no debe exceder las 126 colonias de Escherichia coli por cada $100 \mathrm{ml}$.

Se puede observar una presencia constante de Escherichia coli en todos los sitios examinados y en ambas épocas de estudio evaluadas (época seca y época lluviosa). Según APHA, 2005 la presencia de E.coli en el agua es indicativo de contaminación fecal. Por lo que la presencia de esta en los ríos evidencia una contaminación por residuos orgánicos de origen fecal.

La presencia constante de Escherichia coli en ambas épocas de estudio (Noviembre 2010 y Abril 2011) indican contaminación fecal reciente. La WHO, 1997 menciona que E. coli es abundante en las heces de humanos y animales; y en heces recientes esta puede encontrarse en concentraciones de $10^{9}$ por gramo y que puede ser encontrada en aguas naturales sujetas a contaminación fecal reciente.

Los Enterococos son considerados valiosos indicadores bacterianos para determinar el grado de contaminación fecal de aguas superficiales destinadas a la recreación (APHA, 2005) de ahí la importancia de su estudio en las aguas del Rio Gil González.

En el estudio realizado sobre calidad y disponibilidad del agua de la subcuenca del Río Gil González en el área de influencia Municipal de Belén y Potosí en coordinación con el Centro para la Investigación en Recursos Acuáticos de Nicaragua (CIRA/UNAN), Alcaldía de Belén y Proyecto Sur Oeste, realizado en el periodo 2005 - 2007, las concentraciones de indicadores de contaminación fecal reportadas en los sitios Mata de Caña y Las Mesas para la época seca y lluviosa, fueron inferiores a las reportadas actualmente en los mismos sitios. Este comportamiento evidencia un problema serio de contaminación fecal de origen humano o por animales de sangre caliente (cerdos, gallinas, caballo, ganado) o producto de fecalismo al aire libre.

La presencia de Coliformes termotolerantes en el agua superficial indica la permanencia de contaminación bacteriológica de origen fecal, así mismo las altas concentraciones de Escherichia 
coli observados verifican la presencia de material fecal humana y Enterococos fecales de origen animal.

$\underline{\text { Aguas subterráneas }}$

Pozos excavados

En las regiones rurales los pozos se consideran como inseguros para proveer de agua potable. La contaminación fecal causada por animales puede involucrar riesgos sanitarios, por lo que es importante tener en cuenta los microorganismos más abundantes y frecuentes en las heces de los animales como vaca, cerdo, caballo, gallina y pato.

Los altos crecimientos de Enterococos reportados en los pozos excavados durante las dos épocas de muestreo seguramente estén relacionados a una serie de factores antropogénicos de contaminación como el uso de los suelos para actividades agrícolas, ganaderas, cercanas a los pozos, infiltración de agua residuales provenientes de las letrinas y excrementos de animales, inserción de materia fecal a través de los mecates y baldes sucios que se utilizan para la extracción del agua y deficientes condiciones higiénico sanitarias de la zona.

Actualmente no se cuenta con normas para Enterococos fecales, sin embargo no debería estar presente en el agua de los pozos analizados, la presencia entonces de Enterococos fecales en aguas de consumo humano es una indicación de contaminación fecal y la posible presencia de patógenos entéricos (APHA, 1999).

Las concentraciones bacterianas de Coliformes termotolerantes y Escherichia coli, encontradas en pozos excavados sobrepasaron las normas de la Organización Mundial de la Salud (OMS 1997) y normas CAPRE (1994), que establecen para aguas de consumo humano, la no presencia de bacterias de origen fecal.

La presencia de indicadores en el agua es proporcional al grado de contaminación fecal, ya que mientras más Coliformes termotoleranes y Escherichia coli se aíslen del agua, mayor es la gravedad de la descarga de heces, lo cual genera serios problemas a la salud humana.

Las concentraciones de Coliformes termotolerantes en los pozos sobrepasan las Normas Canadienses que establecen como concentraciones máximas tentativas, 100 Coliformes termotolerantes por $100 \mathrm{ml}$, para aguas de irrigación, a excepción de los pozos ubicados en Mata de Caña, La Cruz o Lagarta y San Antonio, que no sobrepasaron los valores de calidad para riego.

\section{CONCLUSIONES}

En el análisis microbiológico de las aguas de ríos y pozos excavados, los resultados obtenidos durante las dos épocas (seca y lluviosa) demuestran que todos los sitios analizados se encuentran seriamente contaminados por organismos fecales tanto de origen humano como de animales, potenciando esto un alto riesgo a la salud de la población, creándose las condiciones adecuadas para el propagación de enfermedades transmitidas por el agua.

Tanto los ríos como los pozos analizados están contaminados con Coliformes Termotolerantes, Escherichia coli y Enterococos fecales, confirmando que la contaminación presente es producto de 
la presencia de animales, fecalismo al aire libre y de las condiciones higiénico-sanitarias que predominan con el sistema de extracción del agua de los pozos.

Los altos valores de indicadores de origen fecal y el riesgo de contaminación tanto a nivel humano como ambiental hace necesario el control de la calidad microbiológica del agua.

El agua de los pozos no es apta para consumo ni para riego ya que sobrepasan las normas de calidad de agua, así también los ríos se encuentran fuera de los límites permisibles para fines de recreación.

\section{BIBLIOGRAFIA}

American Public Health Association (APHA) 1999. Standard Methods for the Examination of Water and Wastewater. $20^{\text {st }}$. Ed. Washington: APHA

American Public Health Association (APHA) 2005. Standard Methods for the examination of water and wastewater, 21st ed. Washington: APHA.

Arcos P.M.et al. Indicadores microbiológicos de contaminación de las fuentes de agua.

www.unicolmayor.edu.co/invest_nova/NOVA/ARTREVIS2_4.pdf

CIRA/UNAN, Alcaldía de Belén y Proyecto Sur Oeste. 2007. Calidad y Disponibilidad del Agua de la subcuenca del Río Gil González en el área de influencia Municipal de Belén y Potosí.

Comité Coordinador Regional de Instituciones de Agua y Saneamiento de Centro América, Panamá y República Dominicana (CAPRE), 1994. Normas de calidad de agua para consumo humano.

OMS, 1998. Guidelines for drinking-water quality. Second Edition, Volume 3.

Recreational Water Quality Guidelines and Aesthetics, Canadian Council of Ministers of the Environment, 1998.

Surveillance and control of community supplies World Health Organization. Geneva 